\title{
Repressive and Defensive Coping During Fear and Anger
}

\author{
Cornelia A. Pauls and Gerhard Stemmler \\ University of Marburg
}

\begin{abstract}
In this study, the relationship between repressive and defensive coping styles and somatovisceral responses as well as emotion self-reports were investigated in 2 situational contexts conceived to induce fear and anger. Anxiety (State-Trait Anxiety Inventory; L. Laux, P. Glanzmann, P. Schaffner, \& C. D. Spielberger, 1981) $\times$ Defensiveness (Marlowe-Crowne Social Desirability Scale; D. P. Crowne $\&$ D. Marlowe, 1960) $\times$ Emotion (fear, anger) moderated regression analyses revealed that compared with baseline during fear, defensiveness was related to a decrease in heart rate variability. Also during fear, repressive-defensive copers had lower self-reports of negative affect but showed higher behavioral negative affect (m. corrugator reactivity) than other participants. During anger, defensiveness was positively related to both diastolic blood pressure reactivity and m. zygomaticus reactivity. Additional analyses showed that emotional responses of repressivedefensive copers were strongly moderated by the situational context.
\end{abstract}

The history of the repressive-defensive coping style began with the development of the Byrne Repression-Sensitization scale (see Bell \& Byrne, 1978). This measure evolved from the perceptual defense literature (e.g., Eriksen, 1966) in which repressors were defined as individuals who have heightened recognition thresholds for anxiety-provoking stimuli. But soon it emerged that the Byrne scale had limited discriminant validity because of its high correlation with trait anxiety measures (e.g., Weinberger, Schwartz, \& Davidson, 1979).

The repressive coping research progressed with the development of the Marlowe-Crowne (MC) Social Desirability Scale (Crowne \& Marlowe, 1960) that was originally constructed for the assessment of so-

Cornelia A. Pauls and Gerhard Stemmler, Department of Psychology, University of Marburg, Marburg, Germany.

This research was conducted with the help of Deutsche Forschungsgemeinschaft Grant Ste 405/6 and based, in part, on the doctoral thesis of Cornelia A. Pauls. We thank Helga Bauer, Mario Braun, Inke Böddeker, Marcus Heldmann, and Patrick Langer for their help in conducting the study and Thomas Scherer for programming experimental control and data handling.

Correspondence concerning this article should be addressed to Cornelia A. Pauls, Philipps-University of Marburg, Department of Psychology, Gutenbergstr. 18, D-35032 Marburg, Germany. E-mail: pauls@staff.unimarburg.de cially desirable responding as a response style. Within 4 years, however, Crowne and Marlowe (1964) recognized that their scale was primarily measuring a substantive individual difference dimension rather than a response bias. Since that time, a formidable body of research has demonstrated that high-MC scorers generally believe what they are reporting and attempt to behave accordingly (e.g., Derakshan \& Eysenck, 1999; McCrae \& Costa, 1983). However, this insight does not rule out that high-MC scorers can also exaggerate, cheat, and lie, if necessary, to ensure that others recognize their good character or to avoid social disapproval (e.g., Millham, 1974; Paulhus \& John, 1998).

The core motive behind the excessively agreeable and conforming behavior of high-MC scorers seems to be the maintenance of an idealized self-concept, particularly by the defensive avoidance of negative affect such as anxiety or anger (Crowne \& Marlowe, 1964 , pp. 150, 190) and the prevention of threat to self-esteem from anticipated social rejection (e.g., Asendorpf \& Scherer, 1983; Crowne, 1979, p. 169; Weinberger, 1990).

Thus, the MC scale seems to be appropriate for splitting low-trait anxiety scorers into true lowanxious individuals with low MC scale scores and repressors with high MC scale scores, and high-trait anxiety scorers into high-anxious individuals with low $\mathrm{MC}$ scale scores and defensive high-anxious individuals with high MC scale scores. 


\section{Objective Indices of Repressive Coping}

From the beginning of repressive coping research, the main aim was to demonstrate that repressive copers are intrinsically anxious, despite their extremely low self-reported negative affect. It was assumed that their anxiety would be manifested especially in those components of the emotion response that are inaccessible to manipulation such as spontaneously expressed behavioral anxiety and physiological responses.

Studies, which combine emotion self-reports with physiological and behavioral measures, could actually show that repressors compared with the other personality groups showed strong physiological activation and behavioral anxiety but only low scores in selfreported state anxiety when their overly positive selfconcept was threatened (e.g., Asendorpf \& Scherer, 1983; Derakshan \& Eysenck, 1997; Gudjonsson, 1981; Newton \& Contrada, 1992; Weinberger et al., 1979).

However, psychophysiological studies could not always replicate these findings (e.g., Brody, Veit, \& Rau, 1997). One important reason for the inconsistencies in repressive coping research may be the fact that situational contexts and tasks varied from study to study. Newton and Contrada (1992) speculated that verbal-autonomic response dissociation in repressive copers is potentiated by conditions that enhance social-evaluative concerns. Newton and Contrada showed that female repressors exhibited heart rate elevations that were greater in magnitude than their self-reports of negative affect when participants had to give a speech ostensibly observed by three researchers in comparison with a condition in which a single researcher allegedly observed the participants. Barger, Kircher, and Croyle (1997) tried to replicate these results but did not find that repressive coping was moderated by the social-evaluative nature of the context.

In addition, in some studies repressors were confronted with or had to talk about self-conceptthreatening topics (Asendorpf \& Scherer, 1983; Barger et al., 1997; Newton \& Contrada, 1992; Weinberger et al., 1979), which may have been the critical aspect for the heightened physiological reactivity of repressive copers. However, other researchers found effects of repressive-defensive coping even in fairly nonthreatening contexts (e.g., Brown et al., 1996; Gudjonsson, 1981; King, Taylor, Albright, \& Haskell, 1990). Thus, the evidence concerning the key features in the situational context for the activation of repressive-defensive coping is at present unclear.

\section{Repressive-Defensive Coping in Anger-Inducing Situations}

Although it can be assumed that there are a variety of other specific negative affects relevant for repressive-defensive copers, the physiological and behavioral evidence is largely limited to the assessment of anxiety because this state is so readily induced in the laboratory (Weinberger, 1990). According to Weinberger (1990), repressors are characterized not only by low-subjective experience of distress but also by a high level of self-restraint or inhibition of egoistic impulses. In fact, most MC items have little to do with denying distress; rather, they primarily refer to an extreme inhibition of one's own needs when in conflict with the needs of others (Weinberger, 1990). This observation is in line with experiments that show an inhibition of aggressive behavior in high-MC scorers when angered and frustrated (e.g., Fishman, 1965; Taylor, 1970). In addition, when high-MC scorers counteraggressed, they manifested a continued elevation in systolic blood pressure, whereas low-MC scorers manifested a decline in blood pressure (Fishman, 1965). In addition, the MC scale shows its highest correlation with emotional stability, but shows a moderate one also with agreeableness (e.g., McCrae \& Costa, 1983).

Other evidence that repressive-defensive copers have considerable difficulty expressing their needs originates from assertion research (Kiecolt \& McGrath, 1979; Kiecolt-Glaser \& Murray, 1980). Kiecolt-Glaser and Greenberg (1983) assessed participants' physiological reactions to scenes requiring assertiveness. When the participants were asked to imagine responding to the scenes, the repressors had significantly higher increases in diastolic blood pressure than high-anxious or low-anxious groups (defensive high-anxious persons were not investigated). When interacting with a confederate, repressors had greater heart rate changes than the truly low-anxious group.

Embarrassment and shame are emotions that are closely linked to anger. According to Lazarus (1991), shame results when blame is attributed to oneself, whereas anger results when blame is attributed to another person. Miller (1995) demonstrated that individuals who are prone to experience embarrassment reported a heightened concern for others' evaluations, including a fear of negative evaluation, a concern for approval, and a motive to avoid social exclusion. This characterization seems to be fairly in line with that of the approval-seeking and evaluation-dependent per- 
son described by Crowne and Marlowe (1964) and Crowne (1979). According to Bonanno and Singer (1990), repressors are preoccupied with the need for communion and relatedness. In addition, in their model of psychological and physiological health as a function of the balance of interpersonal relatedness and self-esteem, shame is seen as the major affect of repressive copers.

There is some evidence that repressive copers show different coping behavior during embarrassment than during fear. Tremayne and Barry (1994) hypothesized that high repression should function to reduce the level of experienced embarrassment. In this study, female gymnasts had to imagine that something very embarrassing was happening while they were performing their floor routine. Contrary to the author's hypotheses, the negative emotions of the repressors were even accentuated compared with the other groups. According to this finding, defensiveness obviously failed to protect the individual from experienced embarrassment (Tremayne \& Barry, 1994).

\section{Defensiveness Versus Repression}

According to Ritz and Dahme (1996) and Barger et al. (1997), the sample size of the defensive highanxious group is often small because of the low to moderate negative relationship between the MC scale and anxiety scales. Therefore, this group has often not been included in group comparisons (e.g., KiecoltGlaser \& Greenberg, 1983; Newton \& Contrada, 1992; Weinberger et al., 1979). As a consequence, any main effects of defensiveness may be attributed to the repressor group. In other studies that had the potential for a factorial analysis, coping categories were treated as levels of just one factor rather than distributed in a two-factor design (e.g., Asendorpf \& Scherer, 1983; Derakshan \& Eysenck, 1997; King et al., 1990). In fact, there are several studies with psychophysiological parameters as dependent variables that revealed main effects of defensiveness (e.g., Gudjonsson, 1981; Jamner, Shapiro, Goldstein, \& Hug, 1991; Shapiro, Goldstein, \& Jamner, 1995; Tomaka, Blascovich, \& Kelsey, 1992; Warrenburg et al., 1989). Main effects of defensiveness could also be demonstrated for endocrine parameters such as cortisol responses (Al'Absi, Bongard, \& Lovallo, 2000), monocyte (Jamner, Schwartz, \& Leigh, 1988), and $\beta$-endorphin levels (Jamner \& Leigh, 1999), as well as for anterior electroencephalographic activation (Kline, Blackhart, \& Joiner, 2002; Tomarken \& Davidson, 1994). Other researchers found physiological and endocrine effects for repressors only, despite the fact that the defensive high-anxious group was included (Asendorpf \& Scherer, 1983; Barger et al., 1997; Brown et al., 1996; Derakshan \& Eysenck, 1997; Tremayne \& Barry, 1994).

According to our view, the answer to the question, Is repression more important than defensiveness? may depend on the situational context. Situational contexts may have different potentials to activate either repressive or defensive coping. For example, main effects of defensiveness may be expected especially in situations in which the motive to avoid social disapproval is more strongly activated than the motive to avoid negative affect. These are probably situational contexts in which participants are directly confronted with threats of social disapproval such as anger- and embarrassment-inducing situations.

\section{Physiological Variable Selection}

Inconsistencies in the repressive-defensive coping research may also be due to the physiological variable selection. In most studies, heart rate was registered and combined either with systolic and diastolic blood pressure or with measures of electrodermal activity such as the number of spontaneous skin conductance responses (SCRs). It is striking that in nearly all studies in which spontaneous SCRs were recorded, repressors or defensive persons showed higher reactivity during or after threat (Barger et al., 1997; Gudjonsson, 1981; Tomaka et al., 1992; Tremayne \& Barry, 1994; Weinberger et al., 1979). There are also numerous studies that demonstrated repressive-defensive coping effects for heart rate (e.g., Asendorpf \& Scherer, 1983; Derakshan \& Eysenck, 1997; Newton \& Contrada, 1992; Weinberger et al., 1979), diastolic blood pressure (Kiecolt-Glaser \& Greenberg, 1983; Jamner et al., 1991; Shapiro et al., 1995), and systolic blood pressure (Fishman, 1965; King et al., 1990). It should also be noted that most of the studies demonstrating effects for blood pressure were designed to induce anger or frustration, or investigated assertive behavior.

\section{The Present Study}

This brief review of the repressive-defensive coping literature should have made clear that there are many inconsistent findings and obscurities with regard to the impact of the situational context, the boundary conditions for repression versus defensiveness effects, and the physiological variable selection. Therefore, one goal of the present study was to inves- 
tigate the boundary conditions for repression versus defensiveness effects by including all four personality categories, which allowed a separate test of the independent and the interactive effects of anxiety and defensiveness, and by using two situational contexts that were expected to be psychologically meaningful for both defensive and repressive copers.

The second goal of the present study was to select from a more complete array of autonomic variables by registering, in addition to heart rate, spontaneous SCRs and systolic and diastolic blood pressure as well as heart rate variability, preejection period, and total peripheral resistance to capture a broad spectrum of autonomic activity reflecting beta-adrenergic activity (heart rate, systolic blood pressure, preejection period), alpha-adrenergic activity (diastolic blood pressure, total peripheral resistance), as well as general sympathetic activation (number of SCRs), and cardiac activity (heart rate variability; for a discussion of distinct physiological regulation patterns, see Stemmler, 2002). In addition, some of these variables are thought to reflect challenge (heart rate, preejection period) and threat (heart rate, preejection period, diastolic blood pressure, total peripheral resistance) appraisals (Blascovich \& Tomaka, 1996). Thus, differences between challenge and threat should be visible in cardiovascular responses reflecting changes in vascular resistance such as diastolic blood pressure or total peripheral resistance (see, e.g., Blascovich, Mendes, Hunter, \& Salomon, 1999). Behavioral emotion responses were assessed by registering facial activity of the corrugator supercilii and the zygomaticus major muscles. There is some evidence that the activity of the $\mathrm{m}$. corrugator provides information about the expression of negative emotions (for an overview, see Cacioppo, Tassinary, \& Fridlund, 1990), including the expression of anger (Dimberg, 1982; Jaencke, 1996; Vrana, 1994), whereas the activity of the m. zygomaticus indicates the expression of positive emotions $(\mathrm{Ca}-$ cioppo et al., 1990; Dimberg, 1982; Hess, Kappas, McHugo, Kleck, \& Lanzetta, 1989; Sirota, Schwartz, \& Kristeller, 1987; Winkielman \& Cacioppo, 2001) as well as the expression of an embarrassed smile, which, according to Keltner and Buswell (1997), functions to excuse a social transgression or to appease an annoyed person.

The main aim of the present study was to compare emotion responses of repressive-defensive copers during two socially evaluative contexts, conceptualized to induce fear and anger.

Fear was induced by the announcement of giving a speech in several minutes. In contrast to other studies of this kind (Barger et al., 1997; Newton \& Contrada, 1992), in which the observers were not visible for the participant, threat was enhanced by an observer introduced as a "speech expert," sitting directly in front of the participant in order to take notes. In addition, whereas in the Newton and Contrada (1992) as well as the Barger et al. (1997) studies participants had to speak about the most undesirable characteristic of their personality, in this study participants had to talk about a relatively demanding topic concerning the European Union, a topic every socially conscious citizen in Europe should be interested in. Therefore, the risk of appearing intellectually mediocre was very high.

In line with studies in which fear of negative evaluation was induced (Barger et al., 1997; Newton \& Contrada, 1992), we hypothesized that during fear, repressors (or defensive persons) compared with other personality groups would exhibit increased heart rate reactivity and an increase in the number of SCRs. In addition, we predicted that repressors (or defensive persons) would have lower scores in self-reports of fear, strain, displeasure, and the bodily sensation of a pounding heart than would other participants but at the same time show facial expressions of negative affect reflected in an increased activity of the $\mathrm{m}$. corrugator supercilii. This expectation was derived from the Asendorpf and Scherer study in which repressors compared with the low-anxious group showed more facial anxiety during a phrase-association task with affective content (Asendorpf \& Scherer, 1983).

As mentioned above, anger and embarrassment are emotions that are seldom investigated in the context of repressive coping but seem to be psychologically interesting with regard to the approval-seeking character of high-defensive persons. In addition, there is some evidence that repressive-defensive copers respond differently to fear- and anger-inducing situations. In the present study, anger was induced by the direct confrontation with a personal critic, frustration, and unfair accusations, while participants had to perform three cognitively demanding tasks. As indicated above, an anger induction can easily set the stage for the experience of disapproval, embarrassment, and shame because the typically used provocations and accusations aim at temporarily damaging the ought self, for example, through the experimenter's complaints of noncompliance with experimental instructions. This direct confrontation with social disapproval should be very threatening not only for repressors but also for defensive high-anxious persons. In line with the results of studies in which responses to anger, frustration, or assertive behavior 
were investigated (e.g., Fishman, 1965; KiecoltGlaser \& Greenberg, 1983), we expected a positive relationship between defensiveness and blood pressure reactivity. We also hypothesized a negative relationship between defensiveness and $\mathrm{m}$. corrugator activity because there is some evidence that repressive-defensive copers have difficulty with assertiveness and the open expression of anger (e.g., KiecoltGlaser \& Greenberg, 1983; Fishman, 1965; Taylor, 1970). Because defensive persons cannot bear social rejection, we hypothesized that they would try to regain the appreciation from the experimenter and to appease him with smiling. Therefore, we expected a positive relationship between defensiveness and the activity of the m. zygomaticus. Finally, we hypothesized that defensiveness was positively related to self-reported embarrassment and shame.

The statistical procedure used to verify our hypotheses rested on the assumption that some effects theoretically, or for the sake of parsimony should have priority over others. Historically, the repressivedefensive coping concepts can be seen as a refinement of the anxiety concept. Therefore, effects of repressive-defensive coping should be demonstrated beyond those of anxiety. Because the concept of defensive coping is more parsimonious than the repressive coping concept, effects of repressive coping should be demonstrated beyond those of defensive coping. Finally, for each personality effect (anxiety, defensiveness, and the Anxiety $\times$ Defensiveness interaction) we tested whether Personality $\times$ Emotion (fear vs. anger) effects exceeded those of personality effects alone across both emotion conditions.

\section{Method}

\section{Participants}

A sample of 78 healthy women aged 18-45 years $(M=25.2, S D=5.9)$ voluntarily participated in the study. Participants were recruited by flyers distributed on a university campus and by local newspaper ads for a study of stress and strain. The health status of participants was checked by telephone (exclusion criteria were cardiovascular disease, pregnancy, medication affecting the circulation, body mass index outside $23 \pm 5 \mathrm{~kg} / \mathrm{m}^{2}$ ). Psychology students were not included in the sample to reduce the influence of prior experimental participation or knowledge of questionnaires. Participants were paid 45 DM (about \$20) for approximately $3.5 \mathrm{hr}$ of involvement in the study. It was decided to recruit only female participants because earlier research had shown a greater emotional ex- pressiveness in self-reported negative emotions in women than in men (for an overview, see Manstead, 1992). Participants were randomly assigned to fear ( $n$ $=38)$ and anger conditions $(n=40)$.

\section{Personality Questionnaires}

Participants completed a German version of the MC Social Desirability Scale with 23 items (Lück \& Timaeus, 1969) and a German version of the StateTrait Anxiety-Inventory with 20 items (STAI; Laux, Glanzmann, Schaffner, \& Spielberger, 1981). According to the test authors, the MC scale has satisfactory internal consistency (.77). The German STAI has good internal consistency (for different samples between .88 and .94$)$ and good test-retest reliability (.68 and .96 for a time interval between $1 \mathrm{hr}$ and 73 days). According to the test authors, the correlation between the STAI and the German version of the Taylor Manifest Anxiety Scale (Lück \& Timaeus, 1969) is .90 for men and .73 for women, and the correlation with the MC scale is -.24. In the present study, the correlation between the STAI and the MC scale was -.37. Ritz and Dahme (1996) found a correlation of .46 between the German MC scale and a German version of the Rationality/Emotional Defensiveness Scale (Swan, Carmelli, Dame, Rosenman, \& Spielberger, 1991, 1992), which was designed to measure a tendency to avoid negative emotions in interpersonal conflicts and to emphasize logical reasoning as coping strategy in conflicts as well as in life in general. The selfdescriptions of repressors reported by Weinberger et al. (1979) actually showed that these individuals prefer to present themselves as rational and very much in control of their emotions.

\section{Setting and Apparatus}

The experimental room $(4.0 \mathrm{~m} \times 3.4 \mathrm{~m})$ was sound attenuated and air-conditioned and had a largely nontechnical appearance. Participants sat comfortably in a reclined position. Electrodes were connected to a customized headbox (NeuroScan, Herndon, VA), where signals were preamplified with a gain of 30 (input impedance of differential inputs $10 \mathrm{M} \Omega$ ). Transducer-based signals (electrodermal responses, plethysmographic responses, respiration) were relayed through an input box to Biopac (BIOPAC Systems, Santa Barbara, CA) couplers. Biopac voltage was attenuated and then connected to the NeuroScan headbox. Slow-changing signals (electrodermal level, plethysmographic level, skin temperature, and the Z0 signal of the impedance cardiogram) were digitized by the MP 100 of the Biopac system (see below). 
Digitization of all other signals was accomplished with the SynAmps (NeuroScan, Herndon, VA) (see below). Other equipment included, among other things, ${ }^{1}$ two WS-A10E-W Panasonic 160 Watts loudspeakers, a JVC TK-1281 video camera, and a 20-in. (51-cm) black-and-white computer monitor (Miro, Neu-Isenburg, Germany).

In an adjacent room, the following were placed: the 32-channel SynAmps Model 5083 amplifier with 16bit A/D conversion (NeuroScan); a 16-channel Biopac system with couplers for skin conductance (GSR 100), skin temperature (SKT 100), pulse volume (PPG 100), respiration belt (RSP 100), general purpose couplers (DA 100), and an MP 100 workstation with 16-bit A/D conversion; a Kardio-Dynagraph (Diefenbach, Frankfurt am Main, Germany) for impedance cardiography; a Bosotron 2 (Bosch) blood pressure monitor; a Sony minidisk player MDS 501 for the delivery of instructions and loud noise; and other audiovisual equipment. A Macintosh Quadra 950 (Apple) computer with an NB-DI0-24 digital I/O card (National Instruments, Austin, TX) and four serial I/O ports performed experimental control, data recording, data visualization, and data storage under Lab View 3.1.1 (National Instruments) software.

With the exception of parts of the anger condition, participants stayed alone. Whenever necessary, experimenter and participant communicated via intercom.

\section{Procedure}

Introductory session. Participants had the opportunity to familiarize themselves with the experimental room and with standard tests. Then they completed a set of questionnaires, including the MC scale, the STAI, and a questionnaire about general life habits (assessing drug consumption, mental stress factors, etc.), and became acquainted with the emotion selfreport form. Participants were asked to refrain from smoking and drinking coffee or tea for at least $2 \mathrm{hr}$ before the experiment.

Experimental session. One to three weeks after the introductory session, participants performed the experimental session, which lasted approximately 2.5 $\mathrm{hr}$ and was conducted by a male assistant and a male experimenter. In the experimental room, the experimenter explained the introductory tasks and the emotion self-report form. He then asked the participant to sit quietly to help prevent artifacts in the physiological recordings.

The experimental session began with a 10-min rest period, during which participants were expected to relax but keep their eyes open. Following the rest period, participants completed an emotion self-report form.

The anger condition was composed of a 4-min rest period, a 1-min prestimulus period, and three anger induction periods, which were each followed by a 1-min data recording period and then by an emotion self-report. During the first induction period, participants were given a series of 15 items selected for high error rates from a test of general knowledge; they had to say loudly "I don't know" if they did not know an answer. After the second item, which was practically unsolvable, participants were asked to speak louder to compensate for an alleged malfunction in the intercom. After the eighth item, the experimenter interrupted again and said in an annoyed tone that he could not understand the participant. Upon completion of the task, participants were told they completed one third of the test items correctly. After the registration period, the experimenter claimed seeing movement artifacts and reminded the participant to sit quietly. The second induction period was composed of a mental arithmetic task in which participants silently and as quickly as possible subtracted 1, 2, 3, and so forth from 1,000 and the ongoing intermediate results. After $1 \mathrm{~min}$, participants were stopped and told the current result. The experimenter commented on the participant's poor performance and gave her a new start number. One minute later, the participant was stopped again. Again, the result was claimed wrong. After filling out the emotion self-report form, the experimenter grumbled that the participant should state when she was ready, irrespective of whether she had done so or not. During the third induction period, an anagram task was presented on a monitor. After 6 of 12 anagrams, the experimenter quarreled in an angry voice with the participant for moving around in her chair. At the end of the anagram task, the experimenter rudely accused her of noncompliance. After data collection, participants were unhooked, led to another room for a postexperimental interview, and debriefed.

The fear condition started with a 4-min rest period and a 1-min prestimulus period, followed by three fear induction periods and 1-min data recording epochs. The first induction period began with the instruction that participants were to give a 5-min speech on the topic "arguments pro and con the European

\footnotetext{
${ }^{1}$ See Stemmler, Heldmann, Pauls, and Scherer (2001) for details concerning the setting of the experimental rooms.
} 
Community," which should be prepared during the next 5 min without taking notes. Participants were informed that the speech quality would be rated. The second induction period started with the announcement that "a speech expert is now coming into the room to take some notes during the speech." Then the assistant walked into the experimental room, sat down in front of the participant, and prepared to take some notes while displaying a distant and reserved attitude. The third induction period should capture most clearly anticipatory fear. Participants were told that the time for speech preparation was over and that they should wait for a brief moment. During the ensuing minute, physiological data were recorded. Then the signal to start the speech was given. The speech period ended 4 min later, and the assistant left the room. Then the participant was asked to complete the emotion selfreport form retrospectively for the time period immediately before the speech. Finally, participants were unhooked, led to another room for a postexperimental interview, and debriefed.

\section{Variables}

Self-report of emotion. Participants performed an 11-point intensity rating on six unipolar $(0=$ not applicable, $10=$ completely applicable) and five bipolar (from $-5=$ completely applicable via $0=$ not applicable to $5=$ completely applicable) scales, tagged by $1-4$ descriptive adjectives. Five unipolar and two bipolar scales were selected to capture (a) emotional feelings such as embarrassment (embarrassed/ridiculed/ashamed/foolish), fear (frightened/ timid/afraid/scared), sadness (sad/depressed/ miserable/dejected), anger (angry/annoyed/mad/ sour); (b) the bodily sensation of a pounding heart (heartbeat); and (c) feelings of arousal and valence such as strain (calm/relaxed/placid/at ease vs. nervous/restless/tense/wound up) and displeasure (positive/pleasant vs. negative/unpleasant).

Self-reports of emotion were collected at the end of the 10-min rest period and during the fear and anger conditions after each induction period (right after physiological data registration, except for the third induction period of the fear condition, see above).

Physiological variables. For this report, a subsample of 9 out of 29 registered somatovisceral variables were selected.

The electrocardiogram (ECG) was recorded through $\mathrm{Ag} / \mathrm{AgCl}$ surface electrodes $(8 \mathrm{~mm}$ sensor diameter, In Vivo Metric) from a point below the right clavicle and the left lateral margin of the chest. Filters were set to DC and $125 \mathrm{~Hz}$ (12dB/octave), amplifi- cation was 6000 , and sampling rate was $250 \mathrm{~Hz}$. Parameterization was performed with the program BIO25 (Fahrenberg \& Foerster, 1989), yielding heart rate (in beats per minute). Heart rate variability (in milliseconds) was calculated as the square root of the mean square of successive heart period differences, or RMSSD. $^{2}$

The impedance cardiogram (ICG) was recorded with four band electrodes, two placed around the neck and two around the thorax. A current of $0.5 \mathrm{~mA}$ and $33 \mathrm{kHz}$ was fed through the outer electrodes. The $\mathrm{dZ} / \mathrm{dt}$ signal was amplified by 30 , with a filter setting of DC and $125 \mathrm{~Hz}$ and a sampling rate of $250 \mathrm{~Hz}$. Single epoch parameterization was performed with the program BIO25 (Fahrenberg \& Foerster, 1989). Preejection period (in milliseconds) reflects the leftventricular contractile force and was calculated as the time between the Q-wave in the ECG and the B-point in the ICG.

Systolic and diastolic blood pressure (in $\mathrm{mmHg}$ ) were obtained by auscultation in an automatic procedure. The cuff $(50 \mathrm{~cm} \times 13 \mathrm{~cm})$, with an in-built piezo-electrical microphone, was applied on the left arm. Total peripheral resistance (in dyne $\times \mathrm{s} \times \mathrm{cm}^{-5}$ ) was estimated from mean blood pressure divided by cardiac output (in $1 \mathrm{~min}$ ), derived from the ICG.

Electrodermal activity (EDA) was recorded with a constant voltage of $0.5 \mathrm{~V}$ at the volar surface of the proximal phalanxes of the index and ring fingers on the left hand. $\mathrm{Ag} / \mathrm{AgCl}$ electrodes (TSD 103, BIOPAC Systems, Santa Barbara, CA) had a surface of $0.38 \mathrm{~cm}^{2}$; they were filled with a 0.05 molar sodium chloride Unibase emulsion. Sensitivity was 100 $\mu \mathrm{S} / \mathrm{V}$ with a frequency range of $\mathrm{DC}-10 \mathrm{~Hz}$ and a sampling rate of $100 \mathrm{~Hz}$. Phasic responses greater than $0.078 \mu \mathrm{S}$ (minimal slope of $0.007 \mu \mathrm{S} / \mathrm{s}$, maximal half recovery time of $10 \mathrm{~s}$ ) counted as SCRs. BIO25 parameterization yielded the number of SCRs per minute.

Electromyograms (EMG; in microvolts) were obtained from the $\mathrm{m}$. corrugator supercilii and $\mathrm{m}$. zygomaticus major of the left side of the face through $\mathrm{Ag} / \mathrm{AgCl}$ surface electrodes (4 mm sensor diameter,

\footnotetext{
${ }^{2}$ The RMSSD is highly correlated with the high frequency (HF) component derived from spectral analysis, at least for short-term recordings (Task Force, 1996). Compared with lower frequency components, the HF component is the best indicator of vagal activity (see Berntson et al., 1997; Task Force, 1996).
} 
In Vivo Metric). Amplification was 1,000, with filters set to $10 \mathrm{~Hz}$ and $1 \mathrm{kHz}$. After rectification, the signals were low-pass filtered at $40 \mathrm{~Hz}$ (24 dB/octave) and sampled at $100 \mathrm{~Hz}$.

ECG electrode sites were cleansed with alcohol and rubbed with OmniPrep paste to ensure electrode impedances below $10 \mathrm{k} \Omega$. For all electrodes, BIOPAC Sigma Gel 100 electrode paste was used. Participants were grounded at the left mastoid.

Periods of physiological data recording were always 1-min long. For this report, 6 out of 19 periods obtained were chosen: 1st, 2nd, and 9th min of the 10-min rest period, and periods right after each single induction period. ${ }^{3}$

\section{Data Analysis}

Preprocessing of physiological data. Physiological data were analyzed on a beat-by-beat (cardiovascular variables, except blood pressure), 1-s (EMG) or 10 -s basis (number of SCRs) and visually inspected for artifacts. For each participant and variable, medians (all of the ECG- and ICG-derived parameters) or means (EDA and EMG) were calculated per period. Finally, the three induction periods and the three periods of the 10-min rest period were averaged, respectively, to obtain an increased reliability. The baseline for emotion self-reports was the registration right after the 10-min rest period.

Statistical data analysis. First, within the rest period, differences between the fear and the anger group in means of emotion self-reports and physiological activity were tested by using $t$ tests for independent samples and an alpha of .05, two-tailed. To test whether emotion inductions were successful, the average of rest periods were compared with the average of induction periods within each emotion condition by using $t$ tests for dependent samples and an alpha of .05 , two-tailed. To allow a graphical comparison between physiological variables with different metrics, variables were standardized across averaged periods (rest and induction period) and across emotion conditions by using the pooled error standard deviation from a Period (rest, induction) $\times$ Emotion (fear, anger) analysis of variance (ANOVA).

Differences between the fear and the anger conditions were tested with analysis of covariance (ANCOVA), holding constant responses during baseline (average of rest periods). ${ }^{4}$ It should be mentioned that in contrast to difference scores, this procedure results in change scores that are linearly independent of baseline scores.
Instead of dichotomizing the score distribution of the STAI and MC scales and comparing personality group means by using an ANOVA, moderated regressions were calculated with emotion conditions (fear, anger), STAI, MC-defensiveness, and their cross products, as predictors for physiological and selfreport variables. Because of the high correlation between the STAI and the MC, and their product, moderated regressions were calculated with Type I or sequential sum of squares. Type I regression analysis tests the incremental variance of each effect as it is added to the model, the advantage being that the effects embedded into the model can be ordered according to their theoretical importance and that later effects are not partialed from former ones (as in Type III analysis). The following order of effects was devised: (a) the average of rest periods acting as a covariate to adjust for initial differences in the dependent variables, (b) emotion effect, (c) anxiety effect, (d) Anxiety $\times$ Emotion effect, (e) defensiveness effect, (f) Defensiveness $\times$ Emotion effect, $(\mathrm{g})$ Anxiety $\times$ Defensiveness effect, and (h) Anxiety $\times$ Defensiveness $\times$ Emotion effect. This order of effects permitted

\footnotetext{
${ }^{3}$ All periods are described in Stemmler et al. (2001). Standard tests (white noise, handgrip, and exercise task, altogether 10 periods) were not chosen as baseline in this report because we decided to contrast a rest period with the induction period, as it has been done in several other studies concerning repressive coping and defensiveness (e.g., Barger et al., 1997; Shapiro et al., 1995; Tomaka et al., 1992). The 4-min rest and preinduction periods (altogether three periods) were not regarded as baseline periods because these periods had only one or two 1-min data recordings compared with the 10-min rest period with three 1-min data recordings. Therefore, selecting other periods than the 10min rest period would have decreased the reliability of baseline scores. The second fear induction period described by Stemmler et al. (2001) was omitted because it was designed to induce fear of physical harm and therefore differed psychologically from the other three induction periods that were conceived to induce fear of social evaluation.

${ }^{4}$ As described in Stemmler et al. (2001), ANCOVA permits conditional statements about treatment effects for random pretreatment group differences in response level reactivity. ANCOVA may reduce the error variance in group comparisons and consequently increase statistical power. In this study, ANCOVA is a valid statistical procedure to test the null hypothesis of no conditional mean differences among groups because participants were randomly assigned to experimental groups and the covariate (averaged rest periods) was assessed before any differential treatment had begun.
} 
us to test the independent contribution of defensiveness in excess of anxiety effects and the independent contribution of the Anxiety $\times$ Defensiveness interaction, in addition to the anxiety and defensiveness main effects. If one of the effects reached significance, separate moderated regression analyses were calculated (Type I), including all effects up to the significant effect. On the basis of these analyses, contrasts of regression slope differences between fear and anger conditions were calculated as well as simple regressions within or across groups. Sequential regressions were also calculated for responses during the rest period.

A priori hypotheses were tested with simple regressions by using the error variance from the overall moderated regression analysis, including all effects up to the effect being tested and an alpha of .05, onetailed. All other analyses were performed with an alpha of .05, two-tailed.

The interpretation of a significant Anxiety $\times$ Defensiveness interaction was facilitated by the calculation of regression equations for participants with maximal and minimal STAI scores yielding two regression equations for defensiveness as the only predictor. Then, maximal and minimal MC scale scores were entered into these regression equations. Graphically, maximal and minimal defensiveness scores were connected separately for participants with maximal and minimal STAI scores (see also Kelly, Beggs, \& McNeil, 1969). For all analyses, MC and STAI scores were standardized across emotion conditions to allow comparability between regression estimates of the STAI and MC scale and to reduce nonessential ill-conditioning, which may result from the correlation between first-order predictors (e.g., $x$ and $z$ ) and interactions containing those predictors (e.g., $x y$; see West, Aiken, \& Krull, 1996). To test essential illconditioning resulting from high correlations among first-order predictors relationships, tolerances were calculated. According to Myers (1990), multicollinearity is low when the variance inflation factor, the inverse of the tolerance, is lower than 10 (tolerance $=$ $.10)$. Because tolerances ranged between .67 and .95 , our results were not seriously affected by essential ill-conditioning or multicollinearity.

\section{Results}

\section{Manipulation Check: Comparison of Emotion Conditions During Baseline}

Baseline periods did not differ in means of emotion self-reports. However, m. corrugator activity was higher in the fear than in the anger group, $t(76)=$ $2.87, p<.01$.

\section{Manipulation Check: Changes From Baseline}

Physiological variables. In comparison with the rest period, the fear and anger induction resulted in pronounced changes in almost all physiological variables. As shown in Figure 1, during fear, we found an increase in heart rate, $t(37)=10.12, p<.0001$; systolic blood pressure, $t(37)=8.15, p<.0001$; diastolic blood pressure, $t(37)=2.73, p<.01$; as well as a decrease in preejection period, $t(37)=9.20, p<$ .0001 ; and total peripheral resistance, $t(37)=4.85$, $p<.0001$. All of these changes reflect an enhanced cardiac performance accompanied by a decrease in vascular resistance. In addition, we found a decrease in heart rate variability, $t(37)=8.37, p<.0001$, as well as an increase in the number of SCRs, $t(37)=$ $7.34, p<.0001$, reflecting vagal withdrawal and enhanced sympathetic activation, respectively. The $\mathrm{m}$. corrugator activity decreased, $t(37)=5.53, p<$ .0001 ; and $\mathrm{m}$. zygomaticus activity increased, $t(37)=$ 4.25, $p<.0001$.

During anger, we found an increase in heart rate, $t(39)=7.88, p<.0001$, and systolic blood pressure, $t(39)=10.19, p<.0001$; as well as a decrease in

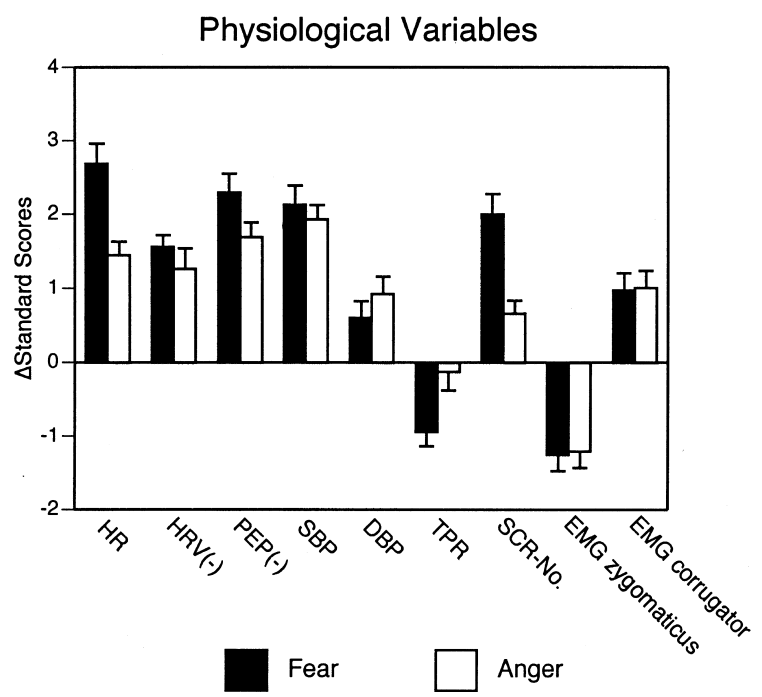

Figure 1. Change scores (induction period minus baseline rest period) from standardized scores during fear and anger. $\mathrm{HR}=$ heart rate; HRV = heart rate variability; PEP = preejection period; $\mathrm{SBP}=$ systolic blood pressure; $\mathrm{DBP}=$ diastolic blood pressure; TPR $=$ total peripheral resistance; SCR-No. = number of skin conductance responses; EMG = electromyogram. Scales for HRV and PEP are inverted, indicating larger activation with decreasing scale scores. 
preejection period, $t(39)=8.32, p<.0001$, reflecting enhanced cardiac performance. At the same time, there was an increase in diastolic blood pressure, $t(39)=4.03, p<.001$. In addition, we found a decrease in heart rate variability, $t(39)=4.91, p<$ .0001 , and an increase in the number of SCRs, $t(39)$ $=3.78, p<.001$. Finally, the $\mathrm{m}$. corrugator activity decreased, $t(39)=5.31, p<.0001$; and the $\mathrm{m}$. zygomaticus activity increased, $t(39)=4.53, p<.0001$ (see Figure 1).

Self-reports of emotions. As shown in Figure 2, during fear, we found increases in self-reported embarrassment, $t(37)=4.52, p<.0001$; fear, $t(37)=$ $3.92, p<.001$; anger, $t(37)=2.99, p<.01$; heartbeat, $t(37)=3.86, p<.001$; strain, $t(39)=9.14$, $p<.0001$; and displeasure, $t(37)=6.49, p<.0001$.

During anger, we found increases in self-reported embarrassment, $t(39)=5.33, p<.0001$; anger, $t(39)$ $=7.88, p<.0001$; strain, $t(39)=6.53, p<.0001$; and displeasure, $t(39)=7.31, p<.0001$. In contrast to the fear condition, self-reported fear and heartbeat did not differ significantly from the rest period.

\section{Manipulation Check: Comparison Between Emotion Conditions}

The comparison of fear and anger groups (see Table 1) indicates that the emotion inductions were successful. Self-reported anger was higher in the an-

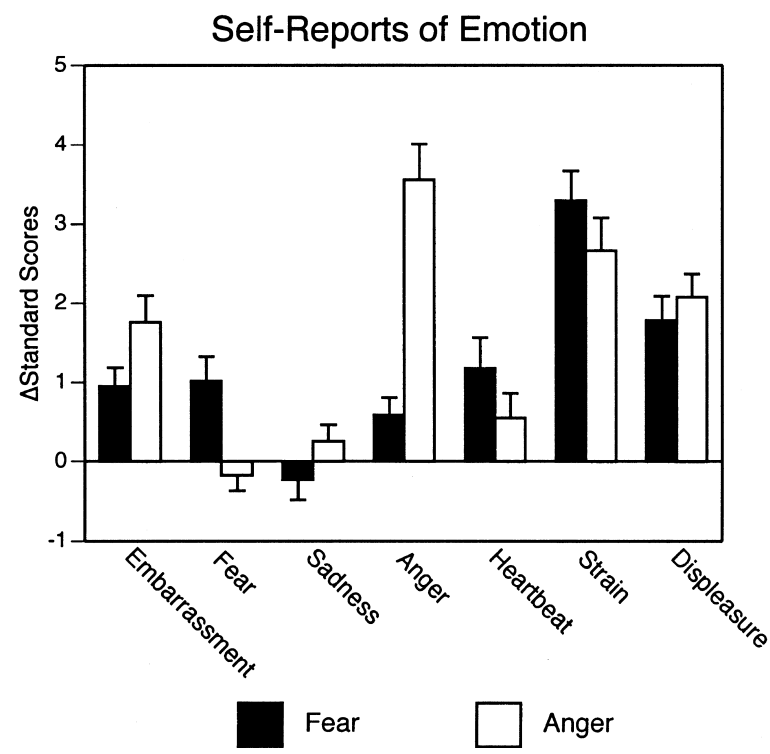

Figure 2. Change scores (induction period minus baseline rest period) from scale scores for emotion self-reports during fear and anger. For bipolar scales (strain, displeasure), a constant of 5 was added. ger group, whereas self-reported fear was higher in the fear group. There were no other significant differences in self-report scales. During fear, heart rate reactivity was higher and SCRs were more frequent than during anger. Total peripheral resistance was higher during anger.

\section{Effects of Repressive-Defensive Coping: Baseline}

For heart rate, we found a significant Anxiety $\times$ Defensiveness interaction in the anger, but not in the fear group (see Table 2). Figure 3 shows that repressors had the highest heart rate, whereas participants with maximal anxiety and defensiveness scores had the lowest.

In addition, the number of SCRs was negatively related to anxiety across both emotion groups. There were no personality or Personality $\times$ Emotion effects for self-reports of emotion.

\section{Effects of Repressive-Defensive Coping: Induction Periods}

A priori hypotheses for physiological variables. It was expected that during fear, repressors (or defensive persons), compared with other personality groups, would exhibit an increased heart rate reactivity, a larger increase in the number of SCRs, as well as an increased activity of the m. corrugator supercilii. As hypothesized, the Anxiety $\times$ Defensiveness effect reached significance for $m$. corrugator activity, $t(69)$ $=3.93, p=.0001$. As expected, repressors exhibited the highest increase in $\mathrm{m}$. corrugator activity compared with all other participants (see Figure 4). For heart rate reactivity and the number of SCRs, our hypothesis could not be confirmed.

During anger, we expected a positive relationship between defensiveness and blood pressure reactivity. In addition, we hypothesized a negative relationship between defensiveness and the activity of the m. corrugator supercilii and a positive relationship with $\mathrm{m}$. zygomaticus activity. As expected, defensiveness was positively related to diastolic blood pressure reactivity, $t(71)=3.29, p<.01$, and $\mathrm{m}$. zygomaticus activity, $t(71)=1.93, p<.05$. For $m$. corrugator activity and systolic blood pressure reactivity, our hypothesis could not be confirmed.

Exploratory analyses for physiological variables. In addition to our a priori hypotheses, we tested whether the relationship between physiological variables and personality was moderated by emotion conditions. As can be seen in Table 3, there was a significant Defensiveness $\times$ Emotion effect for heart rate 
Table 1

Comparison of Emotional Reactivity Between Emotion Conditions

\begin{tabular}{|c|c|c|c|c|c|}
\hline \multirow[b]{2}{*}{ Variable } & \multicolumn{2}{|c|}{ Anger } & \multicolumn{2}{|c|}{ Fear } & \multirow[b]{2}{*}{$F^{\mathrm{a}}$} \\
\hline & $M$ & $S D$ & $M$ & $S D$ & \\
\hline \multicolumn{6}{|c|}{ Self-reports of emotion ${ }^{\mathrm{b}}$} \\
\hline Embarrassment & 2.47 & 2.08 & 1.94 & 1.47 & 1.62 \\
\hline Fear & 0.94 & 1.07 & 2.43 & 1.72 & $21.01 * *$ \\
\hline Sadness & 1.24 & 1.29 & 0.89 & 1.45 & 1.27 \\
\hline Anger & 4.04 & 2.83 & 1.26 & 1.46 & $28.58 * *$ \\
\hline Heartbeat & 3.27 & 1.78 & 3.90 & 1.99 & 2.04 \\
\hline Strain & 1.51 & 1.61 & 1.93 & 1.37 & 1.56 \\
\hline Displeasure & 1.31 & 1.42 & 1.13 & 1.64 & 0.28 \\
\hline \multicolumn{6}{|c|}{ Physiological reactivity $^{\mathrm{b}}$} \\
\hline HR & 89.85 & 10.31 & 101.82 & 16.36 & $14.85 * *$ \\
\hline HRV & 0.86 & 0.86 & 0.74 & 0.66 & 2.28 \\
\hline PEP & 119.30 & 13.41 & 113.28 & 14.70 & 3.52 \\
\hline SBP & 129.58 & 6.21 & 130.26 & 8.64 & 0.16 \\
\hline DBP & 81.33 & 6.71 & 79.63 & 6.36 & 1.30 \\
\hline TPR & 964.01 & 193.15 & 860.31 & 138.70 & $7.24 * *$ \\
\hline SCR-No. & 6.59 & 2.25 & 9.65 & 3.27 & $22.92 * *$ \\
\hline EMG corrugator & 33.69 & 13.70 & 41.07 & 17.79 & 3.79 \\
\hline EMG zygomaticus & 36.16 & 17.15 & 34.53 & 18.54 & 0.16 \\
\hline \multicolumn{6}{|c|}{$\begin{array}{l}\text { Note. Self-reports of embarrassment, fear, sadness, anger, and heartbeat vary from } 0 \text { (not applicable) } \\
\text { to } 10 \text { (completely applicable); self-reports of strain (tense vs. relaxed) and displeasure (positive vs. } \\
\text { negative) vary from }-5 \text { (completely applicable) via } 0 \text { (not applicable) to } 5 \text { (completely applicable). HR } \\
=\text { heart rate; HRV }=\text { heart rate variability; PEP }=\text { preejection period; SBP }=\text { systolic blood pressure; } \\
\text { DBP = diastolic blood pressure; TPR = total peripheral resistance; SCR-No. = number of skin } \\
\text { conductance responses; EMG = electromyogram. } \\
\text { a } d f=2,75 \text {. }^{\text {b }} M \text { and } S D \text { adjusted for the rest period. } \\
* * p<.01 \text { two-tailed. }\end{array}$} \\
\hline
\end{tabular}

variability. During fear, heart rate variability was negatively related to defensiveness, whereas during anger, heart rate variability was slightly positively related to defensiveness $(n s)$. For diastolic blood pressure reactivity, we found a main effect of defensiveness, which was primarily attributable to the positive relationship between defensiveness and diastolic blood pressure reactivity during anger ( $n s$ for the fear

Table 2

Significant Results of the Moderated Anxiety $\times$ Defensiveness $\times$ Emotion Regression Analyses for Physiological Variables During Baseline

\begin{tabular}{llclrl}
\hline Variable & \multicolumn{1}{c}{ Effect } & $F^{\mathrm{a}}$ & Emotion & Estimate & $t^{\mathrm{b}}$ \\
\hline HR & $\mathrm{A} \times \mathrm{D} \times$ Emotion & $4.42^{*}$ & & & \\
& & & Fear & 1.45 & 0.75 \\
& & & Anger & -3.92 & $2.36^{*}$ \\
SCR-No. A & & $4.66^{*}$ & & -0.65 & \\
\hline
\end{tabular}

Note. $\mathrm{A}=$ anxiety; $\mathrm{D}=$ defensiveness; $\mathrm{HR}=$ heart rate; $\mathrm{SCR}$ No. $=$ number of skin conductance responses.

${ }^{\mathrm{a}} d f=7,70 .{ }^{\mathrm{b}} d f=75$ for the anxiety effect, $d f=74$ for the Anxiety $\times$ Emotion effect, $d f=70$ for the Anxiety $\times$ Defensiveness $\times$ Emotion effect.

$* p<.05$, two-tailed.

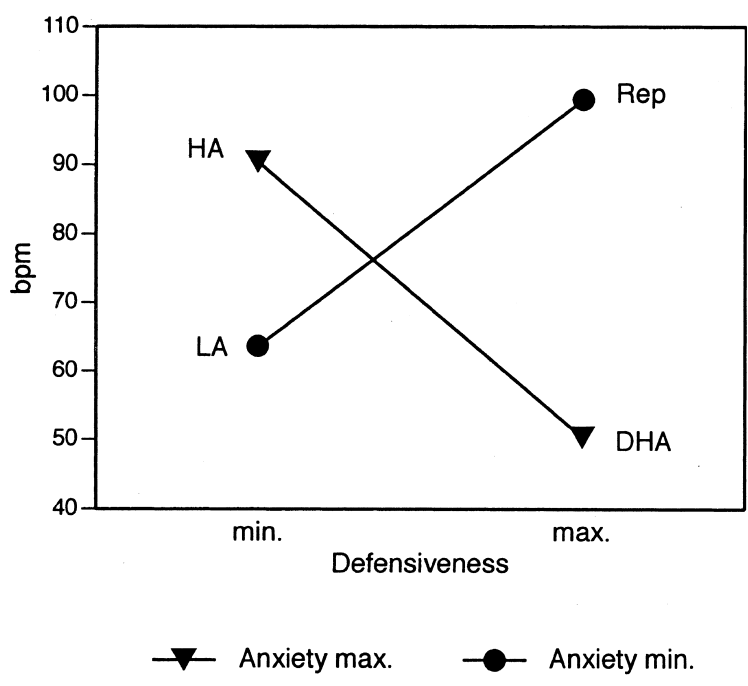

Figure 3. Heart rate responses during baseline within the anger group for persons with a combination of minimal (min.) and maximal (max.) anxiety and defensiveness scores. bpm $=$ beats per minute; Rep $=$ repressors; $\mathrm{LA}=$ low anxious, $\mathrm{HA}=$ high anxious; DHA = defensive high anxious. 

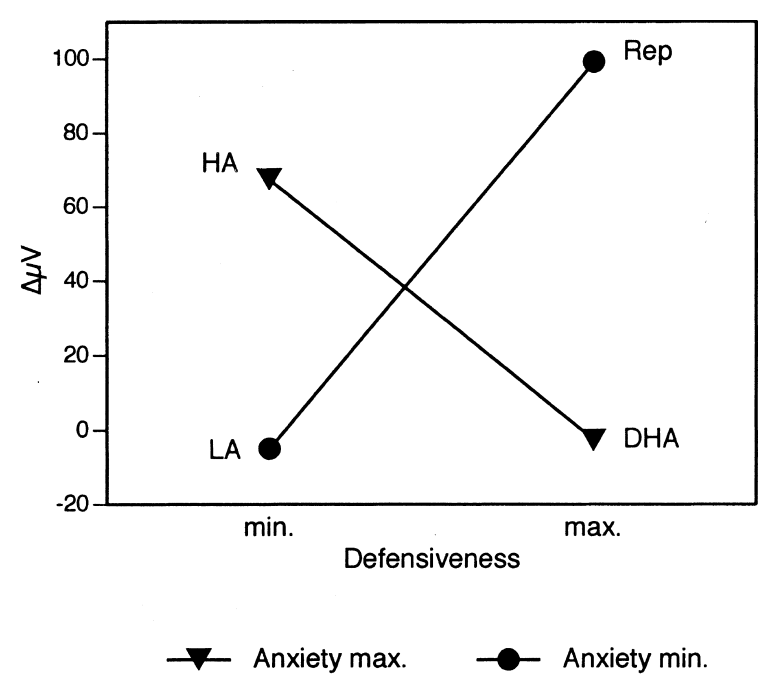

Figure 4. M. corrugator activity (change scores) during fear for persons with a combination of minimal (min.) and maximal (max.) anxiety and defensiveness scores. Rep = repressors; LA = low anxious; HA = high anxious; DHA $=$ defensive high anxious.

condition). During anger, but not during fear, the Anxiety $\times$ Defensiveness effect reached significance for total peripheral resistance reactivity, which was primarily due to defensive high-anxious participants (see Figure 5). M. corrugator activity was negatively related to anxiety across both emotion groups. For $\mathrm{m}$. corrugator activity, we found a significant Defensiveness $\times$ Emotion effect: M. corrugator activity was slightly positively related to defensiveness during fear (ns) and slightly negatively related to defensiveness during anger $(n s)$. Finally, during fear, but not during anger, the Anxiety $\times$ Defensiveness effect reached significance for $\mathrm{m}$. corrugator activity, as well.

A priori hypotheses for self-reports of emotion. We predicted that during fear, repressors (or defensive persons) would have lower scores in self-reports of fear, strain, displeasure, and the bodily sensation of a pounding heart than would other persons. In agreement with this expectation, defensiveness was negatively related to self-reported fear, $t(71)=-2.50$, $p<.01$, and strain, $t(71)=-2.21, p<.05$. The Anxiety $\times$ Defensiveness effect reached significance for self-reported strain, $t(69)=2.09, p<.05$, and displeasure, $t(69)=2.41, p<.01$. As can be seen in Figure 6, repressors had the lowest scores in selfreported strain and displeasure, whereas defensive high-anxious participants had the highest scores in self-reports of these affects. For self-reported heartbeat, our hypothesis could not be confirmed.

The hypothesis that during anger, defensive persons would feel ashamed and embarrassed was also confirmed.

Exploratory analyses for self-reports of emotion. As can be seen in Table 4, the Defensiveness $\times$ Emotion effect reached significance for self-reported embarrassment. Embarrassment was slightly positively related to defensiveness during anger $(n s)$ and slightly negatively related to defensiveness during fear $(n s)$.

Table 3

Significant Results of the Moderated Anxiety $\times$ Defensiveness $\times$ Emotion Regression Analyses for Physiological Variables During Induction Periods

\begin{tabular}{|c|c|c|c|c|c|}
\hline Variable & Effect & $F^{\mathrm{a}}$ & Emotion & Estimate & $t^{\mathrm{b}}$ \\
\hline \multirow[t]{3}{*}{ HRV } & $\mathrm{D} \times$ Emotion & $5.00 *$ & & & \\
\hline & & & Fear & -0.15 & $2.44 *$ \\
\hline & & & Anger & 0.05 & 0.84 \\
\hline DBP & $\mathrm{D}$ & $8.07 * *$ & & 2.14 & \\
\hline \multirow[t]{3}{*}{ TPR } & $\mathrm{A} \times \mathrm{D} \times$ Emotion & $5.53 *$ & & & \\
\hline & & & Fear & -30.00 & 0.93 \\
\hline & & & Anger & 70.17 & $2.52 *$ \\
\hline \multirow{7}{*}{$\begin{array}{l}\text { EMG } \\
\text { corrugator }\end{array}$} & A & $13.89 * *$ & & -6.60 & \\
\hline & $\mathrm{D} \times$ Emotion & $4.62 *$ & & & \\
\hline & & & Fear & 3.33 & 1.33 \\
\hline & & & Anger & -3.90 & 1.46 \\
\hline & $\mathrm{A} \times \mathrm{D} \times$ Emotion & $12.48^{*}$ & & & \\
\hline & & & Fear & 10.34 & $3.93 \dagger+$ \\
\hline & & & Anger & -1.99 & 0.87 \\
\hline
\end{tabular}

Note. $\mathrm{A}=$ anxiety; $\mathrm{D}=$ defensiveness; $\mathrm{HRV}=$ heart rate variability; $\mathrm{DBP}=$ diastolic blood pressure; TPR $=$ total peripheral resistance; $\mathrm{EMG}=$ electromyogram.

${ }^{\mathrm{a}} d f=8,69 .{ }^{\mathrm{b}} d f=72$ for the defensiveness effect, $d f=71$ for the Defensiveness $\times$ Emotion effect, $d f=69$ for the Anxiety $\times$ Defensiveness $\times$ Emotion effect.

$* p<.05 . * * p<.01$, two-tailed. $\dagger \dagger p<.01$, one-tailed. 


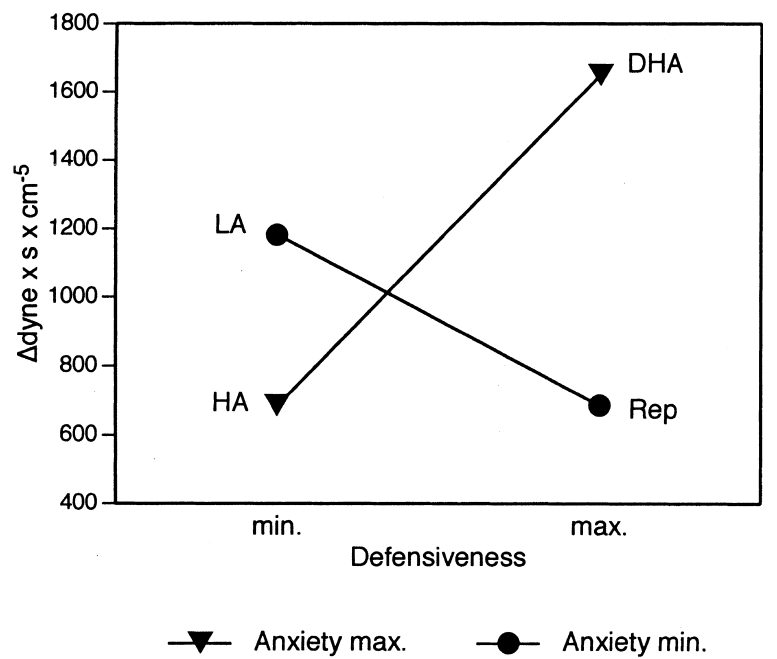

Figure 5. Total peripheral resistance reactivity during anger for persons with a combination of minimal (min.) and maximal (max.) anxiety and defensiveness scores. Rep = repressors; LA = low anxious; HA = high anxious; DHA $=$ defensive high anxious.

The Anxiety $\times$ Emotion effect reached significance for self-reported heartbeat. The sensation of a pounding heart was positively related to anxiety during fear, but not related to anxiety during anger. Finally, for self-reported displeasure, there was a significant Anxiety $\times$ Defensiveness effect, which was primarily attributable to the fear condition ( $n s$ for the anger condition, see Figure 6).

Correlational analyses within personality groups. One interesting question is: How are response dimensions (self-reports of emotion, physiological reactivity, behavioral affect represented by muscle activity) related within each personality group and emotion induction condition? Because the following analyses were performed for exploratory purposes, we decided to calculate simple correlation coefficients rather than moderator analyses to get a clearer picture of the relationships between response dimensions within Personality $\times$ Emotion groups. To contain the number of statistical tests, we calculated an index for selfreported negative affect by averaging self-reported fear, heartbeat, strain, and displeasure. The intercorrelations for these self-report variables ranged between .40 and .73 for the fear, and .27 to .68 for the anger conditions. The correlation between selfreported negative affect and self-reported embarrassment in the fear and anger conditions were $.49(p<$ $.01)$ and $.71(p<.01)$, respectively. For self-reported anger, the correlations were $.35(p>.05)$ for the fear, and $.66(p<.01)$ for the anger condition. Physiological variables were baseline adjusted and $z$-standardized, except for the number of SCRs indicating general sympathetic activation and heart rate variability reflecting cardiac tone. We averaged $z$-standardized scores of heart rate, preejection period (reversed in sign), and systolic blood pressure, yielding an index for beta-adrenergic reactivity. We calculated an index of vascular or alpha-adrenergic reactivity by averaging $z$-standardized responses of diastolic blood pressure and total peripheral resistance. The intercorrelations of the physiological variables composed of each of the indexes ranged between $|r|=.62$ to .72 for beta-adrenergic activity and were .41 for alphaadrenergic activity in the fear condition. In the anger condition, the intercorrelations ranged between $|r|=$ .49 and .59 for beta-adrenergic activity and were .39 for alpha-adrenergic activity. On the basis of median splits on the MC scale and the STAI, participants
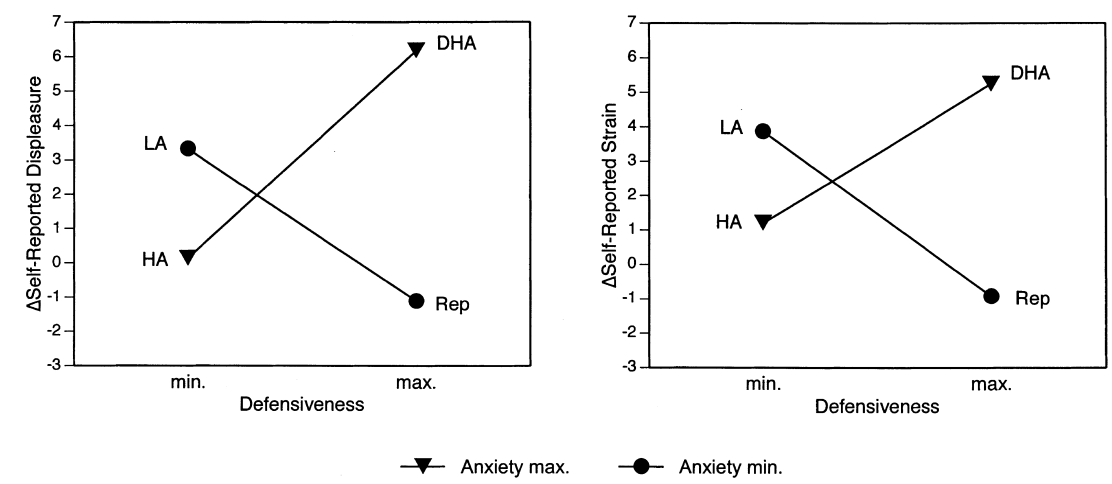

Figure 6. Self-reported displeasure and strain during fear for persons with a combination of minimal (min.) and maximal (max.) anxiety and defensiveness scores. Rep = repressors; LA $=$ low anxious; HA $=$ high anxious; DHA $=$ defensive high anxious. 
Table 4

Significant Results of the Moderated Anxiety $\times$ Defensiveness $\times$ Emotion Regression Analyses for Emotion Self-Reports During Induction Periods

\begin{tabular}{ccclrc}
\hline Variable & Effect & $F^{\mathrm{a}}$ & Emotion & Estimate & $t^{\mathrm{b}}$ \\
\hline $\begin{array}{c}\text { Embarrass- } \\
\text { ment }\end{array}$ & $\mathrm{D} \times$ Emotion & $5.34^{*}$ & & & \\
& & & Fear & -0.53 & 1.69 \\
Heartbeat & $\mathrm{A} \times$ Emotion & $5.85^{*}$ & Anger & 0.52 & 1.59 \\
& & & Fear & 0.87 & $2.44^{*}$ \\
& & & Anger & -0.22 & 0.78 \\
Displeasure & $\mathrm{A} \times \mathrm{D}$ & $5.32^{*}$ & & 0.44 & \\
\hline
\end{tabular}

Note. $\mathrm{A}=$ anxiety; $\mathrm{D}=$ defensiveness.

${ }^{\mathrm{a}} d f=8,69 .{ }^{\mathrm{b}} d f=73$ for the Anxiety $\times$ Emotion effect, $d f=71$ for the Defensiveness $\times$ Emotion effect, $d f=70$ for the Anxiety $\times$ Defensiveness effect.

$* p<.05$, two-tailed.

were classified into low-anxious $(n=9$ in the fear and $n=9$ in the anger group), high-anxious ( $n=8$ in the fear and $n=12$ in the anger group), defensive high-anxious ( $n=10$ in the fear and $n=9$ in the anger group), and repressor groups ( $n=11$ in the fear and $n=10$ in the anger group). Because of the small sample size within each Personality $\times$ Emotion group, scatterplots were visually inspected for outliers by imposing a 95\% bivariate normal density ellipse on each scatterplot. Outliers were excluded from further analyses.

Correlational analyses between response dimensions revealed that for repressors in the fear condition, self-reported negative affect was negatively related to alpha-adrenergic reactivity $(r=-.74, p<.01)$. Thus, a low self-report of negative affect was accompanied by strong increases in alpha-adrenergic activity. During anger, beta-adrenergic activity was positively related to $\mathrm{m}$. corrugator activity $(r=.70, p<.05)$.

For defensive high-anxious participants in the fear condition, self-reported negative affect was strongly positively related to $\mathrm{m}$. corrugator activity $(r=.82$, $p<.01)$.

For low-anxious participants in the anger condition, self-reported negative affect was positively related to m. zygomaticus activity $(r=.77, p<.05)$, and betaadrenergic activity was strongly positively related to $\mathrm{m}$. corrugator activity $(r=.85, p<.01)$. It should be mentioned that we found a similar relationship for repressors in the anger condition (see above).

Finally, for high-anxious participants in the fear condition, self-reported negative affect was positively related to $\mathrm{m}$. corrugator activity $(r=.78, p<.05)$. We found similar relationship for the defensive highanxious group (see above). During anger, selfreported negative affect was positively related to beta- adrenergic activity ( $r=.64, p<.05)$, to $\mathrm{m}$. corrugator activity $(r=.72, p<.01)$, and was negatively related to $\mathrm{m}$. zygomaticus activity $(r=-.63, p<.05)$.

\section{Discussion}

Results obtained during fear partly confirm those that had been found in other studies in which socially evaluative threat was induced (Barger et al., 1997; Newton \& Contrada, 1992) or in which repressors or defensive persons had to deal with self-conceptthreatening topics (e.g., Asendorpf \& Scherer, 1983; Weinberger et al., 1979). It was expected that during fear, repressors (or defensive persons), compared with other personality groups, would exhibit an increased heart rate reactivity and a larger increase in the number of SCRs as well as an increased $\mathrm{m}$. corrugator activity. We also predicted that repressors (or defensive persons) would have lower scores in self-reported negative affect such as emotion self-reports of fear, strain, displeasure, and the bodily sensation of a pounding heart. In line with these expectations, repressors compared with all other participants showed the largest increase in $\mathrm{m}$. corrugator activity and had the lowest scores in self-reported strain and displeasure. However, for heart rate and the number of SCRs, our hypotheses could not be confirmed.

During anger, participants were directly confronted with social disapproval, which was expected to be very threatening not only for repressors but also for defensive high-anxious participants. In line with the results of those studies, in which we investigated responses to anger, frustration, or assertive behavior (e.g., Fishman, 1965; Kiecolt-Glaser \& Greenberg, 1983), we expected a positive relationship between defensiveness and blood pressure reactivity. Because some studies demonstrated that repressive-defensive copers have difficulty with assertiveness and the open expression of anger (e.g., Fishman, 1965; KiecoltGlaser \& Greenberg, 1983; Taylor, 1970), we hypothesized a negative relationship between defensiveness and $\mathrm{m}$. corrugator activity. In addition, we expected a positive relationship between defensiveness and $\mathrm{m}$. zygomaticus activity. This hypothesis was derived from the assumption that defensive persons would try to regain the appreciation from the experimenter and to appease him with smiling. Finally, we hypothesized a positive relationship between defensiveness and self-reported embarrassment and shame. In accordance with these expectations, defensiveness was positively related to diastolic blood pressure reactivity. According to the model of Blascovich and To- 
maka (1996), this may indicate that high compared with low-defensive copers appraised the situation as rather threatening. Defensiveness was also positively related to $\mathrm{m}$. zygomaticus activity, but not to $\mathrm{m}$. corrugator activity, self-reported embarrassment, or shame.

An important prerequisite for the investigation of repressive-defensive coping strategies during fear and anger was the successful induction of these emotions. Results demonstrated that this goal was met. The comparison of the baseline rest period with the induction period revealed strong changes in almost all dependent variables during fear and anger.

In addition, it could be shown that self-reported fear was higher in the fear condition, and self-reported anger was higher in the anger condition. Concerning physiological variables, total peripheral resistance reactivity was higher during anger than during fear, whereas heart rate and the number of SCRs reactivity was higher during fear compared with anger.

Exploratory analyses during induction periods should reveal differences in the relationship between the dependent variables and personality during fear and anger. By and large, results of these analyses showed that during anger, emotional responses of defensive persons differed considerably from those found during fear. During fear, but not during anger, defensiveness was negatively related to heart rate variability, indicating stronger vagal withdrawal for high- compared with low-defensive persons. During anger, but not during fear, defensive high-anxious participants compared with other personality groups showed a marked increase in total peripheral resistance. As expected, the relationship between defensiveness and the Anxiety $\times$ Defensiveness interaction on the one hand and $\mathrm{m}$. corrugator activity on the other hand was also moderated by emotion conditions: M. corrugator activity was slightly positively related to defensiveness during fear and slightly negatively related to defensiveness during anger, and the Anxiety $\times$ Defensiveness effect reached significance for the fear, but not for the anger condition. Concerning emotion self-reports, defensiveness was slightly negatively related to embarrassment during fear, but slightly positively related to embarrassment during anger.

Overall, our results showed that the physiological, emotional, and behavioral response patterns of repressive-defensive copers strongly depended on the situational context realized. The most striking result of the present study was that during fear, repressivedefensive copers compared with other personality groups showed high-behavioral and low self-reported negative affect. However, during anger, highdefensive copers showed low-behavioral negative affect and even slightly higher self-reported negative affect (e.g., self-reported embarrassment) compared with low-defensive participants.

According to Weinberger (1990), contexts in which repressors release their defenses have not yet been identified. However, results of this study suggest that for high-MC scorers, the direct confrontation with disapproval, failure, and personal critique expressed by an experimenter may result in an inability to avoid the threatening aspects of the situation. This interpretation is in line with a study of Baumeister and Cairns (1992) in which low-anxious and high-anxious participants as well as repressors were confronted with positively and negatively valenced bogus personality feedback that was allegedly either public (participants were told that the data would be shown to their experimental partners) or private. The main dependent variable was the amount of time participants spent reading their personality feedback. It could be shown that repressors who received threatening feedback privately spent the least time reading it, whereas repressors who received the same feedback publicly spent a long time reading it. With a thought-listing procedure, it was demonstrated that repressors in the public condition thought and worried about the partner's (bad) impression of them, whereas the nonrepressors were unaffected by the favorability of the evaluation or of the public nature of the situation. This study showed that repressors prefer an avoidant self-deceiving strategy when they receive negative feedback privately, but when self-image-threatening information is public knowledge, they pay close attention to it, think about possible refutations, and ruminate particularly about how other people perceive them. Thus, the audience prevented repressors from ignoring threatening feedback. Even though the authors did not assess selfreports of emotion, it is likely that repressors felt quite embarrassed and ashamed in this situation (see also Tremayne \& Barry, 1994). Unfortunately, Baumeister and Cairns (1992) had not included the defensive high-anxious group, and therefore it is unclear whether their results would also apply to high-MC scorers in general.

The results of the Baumeister and Cairns study are in line with the considerations of Paulhus (1984), according to whom the MC scale represents a mixture of contrasting, and possibly conflicting, coping strategies within the same individual. Similarly, according to Warrenburg et al. (1989), high-MC scorers pursue opposite cognitive strategies as they strive defensively 
both to protect their fragile self-esteem and to avoid social disapproval. Intrapersonally, they would need to avoid anxiety-arousing thoughts and feelings related to poor self-esteem; interpersonally, they would need to attend to the potential revelation of these cognitions so that they could attempt to avoid social disapproval by managing their impression on others. These considerations implicate that in contexts in which repressive-defensive copers are publicly confronted with social disapproval, they seem to have a defensive need for positive self-presentation and impression management (Bonanno \& Singer, 1990). This interpretation is also in line with our finding that during anger, high- compared with low-defensive persons smiled to appease the annoyed experimenter.

Another striking result of the present study was that main effects of defensiveness emerged not only during anger but also during fear, possibly because of the strong socially evaluative nature of the fear condition, which might have been threatening not only for repressors but also for high-MC scorers in general. In addition, the defensive high-anxious group showed the strongest increases in negative affect during fear as well as the strongest increases in total peripheral resistance during anger. These results implicate that for future research, it is worthwhile to include the defensive high-anxious group and to analyze effects of defensiveness in addition to repression effects.

Although our results seem to be promising for the study of repressive coping and defensiveness, it should be mentioned that the generalizability of our results is constrained by the fact that we studied only female participants, the majority of whom were university students. Concerning the gender of the participants, Kline, Allen, and Schwartz (1998) showed that during the rest period, defensiveness correlated positively with relative left frontal electroencephalographic activation in women (see also Tomarken \& Davidson, 1994), whereas high-defensive men showed relative right frontal activation. Jamner and Leigh (1999) found that defensiveness was positively correlated with resting plasma $\beta$-endorphin levels and responses in men, but not in women. In addition, Kline et al. (2002) found that defensiveness was associated with greater relative left frontal activation in the presence of opposite-sex, but not same-sex experimenters. Because relative left frontal activation has been associated with behavioral approach motivation (e.g., Davidson, Ekman, Saron, Senulis, \& Friesen, 1990), Kline et al. (2002) assumed that in the opposite-sex condition high- compared with low-defensive individuals were more strongly inclined toward posi- tive self-presentation. These results imply that the nature of defensiveness as a coping strategy may vary as a function of gender as well as a function of the gender by testing situation interaction.

Despite this caveat, our study has notable implications for future research. First, the sequential moderated regression analysis approach used in this study has several advantages compared with the conventional ANOVA approach. First, the moderated regression analysis approach has increased statistical power compared with a group design. Second, this approach avoids the problems typically associated with the rather artificial assignment of participants to certain personality groups. Third, it circumvents the problems associated with the two-dimensional classification of participants when personality scales are correlated. Finally, the Type I regression procedure has the particular advantage of having easily interpreted effects that can be tested according to a theoretical model.

In addition, the present study has shown that it is worthwhile to investigate defensiveness alone and in combination with trait anxiety. Furthermore, this study has demonstrated that future research should realize situational contexts that bear an influence differently on defensive versus repressive copers (e.g., contexts in which participants receive private and public negative evaluation). Third, this study has shown that it is worthwhile to select a broader array of physiological, but also self-report variables. Fourth, to investigate whether defensive-repressive copers actually pursue different strategies to protect their fragile self-esteem and to avoid social disapproval, it would be necessary to investigate the same participants in two situational contexts that activate these strategies to determine whether repressive-defensive copers actually change their coping strategies with avoidance of negative affect in one situation and positive selfpresentation in another situation, or whether they consistently use one coping style across situations.

\section{References}

Al'Absi, M., Bongard, S., \& Lovallo, W. R. (2000). Adrenocorticotropin responses to interpersonal stress: Effects of overt anger expression style and defensiveness. International Journal of Psychophysiology, 37, 257-265.

Asendorpf, J. B., \& Scherer, K. R. (1983). The discrepant repressor: Differentiation between low anxiety, high anxiety, and repression of anxiety by autonomic-facialverbal patterns of behavior. Journal of Personality and Social Psychology, 45, 1334-1346.

Barger, S. D., Kircher, J. C., \& Croyle, R. T. (1997). The 
effects of social context and defensiveness on the physiological responses of repressive copers. Journal of Personality and Social Psychology, 73, 1118-1128.

Baumeister, R. F., \& Cairns, K. J. (1992). Repression and self-presentation: When audiences interfere with selfdeceptive strategies. Journal of Personality and Social Psychology, 62, 851-862.

Bell, P. A., \& Byrne, D. (1978). Repression-sensitization. In H. London \& J. E. Exner Jr. (Eds.), Dimensions of personality (pp. 449-485). New York: Wiley.

Berntson, G. G., Bigger, J. T. J., Eckberg, D. L., Grossman, P., Kaufmann, P. G., Malik, M., et al. (1997). Heart rate variability: Origins, methods, and interpretive caveats. Psychophysiology, 34, 623-648.

Blascovich, J., Mendes, W. B., Hunter, S. B., \& Salomon, K. (1999). Social "facilitation" as challenge and threat. Journal of Personality and Social Psychology, 77, 68-77.

Blascovich, J., \& Tomaka, J. (1996). The biopsychosocial model of arousal regulation. Advances in Experimental Social Psychology, 28, 1-51.

Bonanno, G. A., \& Singer, J. L. (1990). Repressive personality style: Theoretical and methodological implications for health and pathology. In J. L. Singer (Ed.), Repression and dissociation: Implications for personality theory, psychopathology, and health (pp. 435-470). Chicago: University of Chicago Press.

Brody, S., Veit, R., \& Rau, H. (1997). Lie scores are associated with less cardiovascular reactivity to baroreceptor stimulation and to mental arithmetic stress. Personality and Individual Differences, 22, 677-681.

Brown, L. L., Tomarken, A. J., Orth, D. N., Loosen, P. T., Kalin, N. H., \& Davidson, R. J. (1996). Individual differences in repressive-defensiveness predict basal salivary cortisol levels. Journal of Personality and Social Psychology, 70, 362-371.

Cacioppo, J. T., Tassinary, L. G., \& Fridlund, A. J. (1990). The skeletomotor system. In J. T. Cacioppo \& L. G. Tassinary (Eds.), Principles of psychophysiology: Physical, social, and inferential elements (pp. 325-384). New York: Cambridge University Press.

Crowne, D. P. (1979). The experimental study of personality. New York: Wiley.

Crowne, D. P., \& Marlowe, D. (1960). A new scale of social desirability independent of psychopathology. Journal of Consulting Psychology, 24, 349-354.

Crowne, D. P., \& Marlowe, D. (1964). The approval motive. New York: Wiley.

Davidson, R. J., Ekman, P., Saron, C. D., Senulis, J. A., \& Friesen, W. V. (1990). Approach-withdrawal and cerebral asymmetry: Emotional expression and brain physiology: I. Journal of Personality and Social Psychology, $58,330-341$.
Derakshan, N., \& Eysenck, M. W. (1997). Interpretive biases for one's own behavior and physiology in high-traitanxious individuals and repressors. Journal of Personality and Social Psychology, 73, 816-825.

Derakshan, N., \& Eysenck, M. W. (1999). Are repressors self-deceivers or other-deceivers. Cognition and Emotion, 13, 1-17.

Dimberg, U. (1982). Facial reactions to facial expressions. Psychophysiology, 19, 643-647.

Eriksen, C. W. (1966). Cognitive responses to internally cued anxiety. In C. D. Spielberger (Ed.), Anxiety and behavior. New York: Academic Press.

Fahrenberg, J., \& Foerster, F. (1989). Nicht-invasive Methodik für die kardiovasculäre Psychophysiologie [Noninvasive methods for cardiovascular psychophysiology]. Frankfurt, Germany: Lang.

Fishman, C. G. (1965). Need for approval and the expression of aggression under varying conditions of frustration. Journal of Personality and Social Psychology, 2, 809-816.

Gudjonsson, G. H. (1981). Self-reported emotional disturbance and its relation to electrodermal reactivity, defensiveness and trait anxiety. Personality and Individual Differences, 2, 47-52.

Hess, U., Kappas, A., McHugo, G. J., Kleck, R. E., \& Lanzetta, J. T. (1989). An analysis of the encoding and decoding of spontaneous and posed smiles: The use of facial electromyography. Journal of Nonverbal Behavior, 13, 121-137.

Jaencke, L. (1996). Facial EMG in an anger-provoking situation: Individual differences in directing anger outwards or inwards. International Journal of Psychophysiology, 23, 207-214.

Jamner, L. D., \& Leigh, H. (1999). Repressive/defensive coping, endogenous opioids and health: How a life so perfect can make you sick. Psychiatry Research, 85, 1731.

Jamner, L. D., Schwartz, G. E., \& Leigh, H. (1988). The relationship between repressive and defensive coping styles and monocyte, eosinophiles, and serum glucose levels: Support for the opioid peptide hypothesis of repression. Psychosomatic Medicine, 50, 567-575.

Jamner, L. D., Shapiro, D., Goldstein, I. B., \& Hug, R. (1991). Ambulatory blood pressure and heart rate in paramedics: Effects of cynical hostility and defensiveness. Psychosomatic Medicine, 53, 393-406.

Kelly, F. J., Beggs, D. L., \& McNeil, K. A. (1969). Multiple regression approach. Carbondale \& Edwardsville: Southern Illinois University Press.

Keltner, D., \& Buswell, B. N. (1997). Embarrassment: Its distinct form and appeasement functions. Psychological Bulletin, 122, 250-270. 
Kiecolt, J. K., \& McGrath, E. (1979). Social desirability in the measurement of assertive behavior. Journal of Consulting and Clinical Psychology, 47, 640-642.

Kiecolt-Glaser, J. K., \& Greenberg, B. (1983). On the use of physiological measures in assertion research. Journal of Behavioral Assessment, 5, 97-109.

Kiecolt-Glaser, J. K., \& Murray, J. A. (1980). Social desirability bias in self-monitoring data. Journal of Behavioral Assessment, 2, 239-247.

King, A. C., Taylor, C. B., Albright, C. A., \& Haskell, W. L. (1990). The relationship between repressive and defensive coping styles and blood pressure responses in healthy, middle-aged men and women. Journal of Psychosomatic Research, 34, 461-471.

Kline, J. P., Allen, J. J. B., \& Schwartz, G. E. (1998). Is left frontal brain activation in defensiveness gender specific? Journal of Abnormal Psychology, 107, 149-153.

Kline, J. P., Blackhart, G. C., \& Joiner, T. E. (2002). Sex, lie scales, and electrode caps: An interpersonal context for defensiveness and anterior electroencephalographic asymmetry. Personality and Individual Differences, 33, 459-478.

Laux, L., Glanzmann, P., Schaffner, P., \& Spielberger, C. D. (1981). Das State-Trait-Angstinventar [The StateTrait-Anxiety Inventory]. Weinheim, Germany: Beltz.

Lazarus, R. S. (1991). Emotion and adaptation. New York: Oxford University Press.

Lück, H. E., \& Timaeus, E. (1969). Skalen zur Messung manifester Angst (MAS) und sozialer Wünschbarkeit (SDS-E und SDS-CM) [Scales for the assessment of manifest anxiety (MAS) and social desirability (SDS-E and SDS-CM)]. Diagnostica, 15, 134-137.

Manstead, A. S. R. (1992). Gender differences in emotion. In A. Gale \& M. W. Eysenck (Eds.), Handbook of individual differences: Biological perspectives (pp. 355387). Chichester, England: Wiley.

McCrae, R. R., \& Costa, P. T. (1983). Social desirability scales: More substance than style. Journal of Consulting and Clinical Psychology, 51, 882-888.

Miller, R. S. (1995). On the nature of embarrassability: Shyness, social evaluation, and social skill. Journal of Personality, 63, 315-339.

Millham, J. (1974). Two components of need for approval score and their relationship to cheating following success and failure. Journal of Research in Personality, 8, 378392.

Myers, R. H. (1990). Classical and modern regression with applications (2nd ed.). Boston: Duxbury Press.

Newton, T. L., \& Contrada, R. J. (1992). Repressive coping and verbal-autonomic response dissociation: The influence of social context. Journal of Personality and Social Psychology, 62, 159-167.
Paulhus, D. L. (1984). Two-component models of socially desirable responding. Journal of Personality and Social Psychology, 46, 598-609.

Paulhus, D. L., \& John, O. P. (1998). Egoistic and moralistic bias in self-perception: The interplay of self-deceptive styles with basic traits and motives. Journal of Personality, 66, 1025-1060.

Ritz, T., \& Dahme, B. (1996). Repression, self-concealment and rationality/emotional defensiveness: The correspondence between three questionnaire measures of defensive coping. Personality and Individual Differences, 20, 95102.

Shapiro, D., Goldstein, I. B., \& Jamner, L. D. (1995). Effects of anger/hostility, defensiveness, gender, and family history of hypertension on cardiovascular reactivity. Psychophysiology, 32, 425-435.

Sirota, A. D., Schwartz, G. E., \& Kristeller, J. L. (1987). Facial muscle activity during induced mood states: Differential growth and carry-over of elated versus depressed patterns. Psychophysiology, 24, 691-699.

Stemmler, G. (2002). Methodological considerations in the psychophysiological study of emotion. In R. J. Davidson, H. H. Goldsmith, \& K. R. Scherer (Eds.), Handbook of affective science (pp. 225-255). New York: Oxford University Press.

Stemmler, G., Heldmann, M., Pauls, C. A., \& Scherer, T. (2001). Constraints for emotion specificity in fear and anger: The context counts. Psychophysiology, 38, 275291.

Stemmler, G., Schäfer, H., \& Marwitz, M. (1993). Zum Konzept und zu den Operationalisierungen von Stilen der Ärgerverarbeitung [Concerning the concept and operationalization of anger coping styles]. In V. Hodapp \& P. Schwenkmezger (Eds.), Ärger und Ärgerausdruck [Anger and anger expression] (pp. 71-111). Bern, Switzerland: Huber.

Swan, G. E., Carmelli, D., Dame, A., Rosenman, R. H., \& Spielberger, C. D. (1991). The Rationality/Emotional Defensiveness Scale: I. Internal structure and stability. Journal of Psychosomatic Research, 35, 545-554.

Swan, G. E., Carmelli, D., Dame, A., Rosenman, R. H., \& Spielberger, C. D. (1992). The Rationality/Emotional Defensiveness Scale: II. Convergent and discriminant correlational analysis in males and females with and without cancer. Journal of Psychosomatic Research, 36, 349359.

Task Force of the European Society of Cardiology (ESC) and the North American Society of Pacing and Electrophysiology (NASPE). (1996). Heart rate variability: Standards of measurement, physiological interpretation, and clinical use. European Heart Journal, 17, 354-381.

Taylor, S. (1970). Aggressive behavior as a function of 
approval motivation and physical attack. Psychonomic Science, 18, 195-196.

Tomaka, J., Blascovich, J., \& Kelsey, R. M. (1992). Effects of self-deception, social desirability, and repressive coping on psychophysiological reactivity to stress. Personality and Social Psychology Bulletin, 18, 616-624.

Tomarken, A. J., \& Davidson, R. J. (1994). Frontal brain activation in repressors and nonrepressors. Journal of Abnormal Psychology, 103, 339-349.

Tremayne, P., \& Barry, R. J. (1994). Repressive defensiveness and trait anxiety effects in an orienting task with a manipulation of embarrassment. Anxiety, Stress and Coping, 7, 35-52.

Vrana, S. R. (1994). Startle reflex response during sensory modality specific disgust, anger, and neutral imagery. Journal of Psychophysiology, 8, 211-218.

Warrenburg, S., Levine, J., Schwartz, G. E., Fontana, A. F., Kerns, R. D., Delaney, R., \& Mattson, R. (1989). Defensive coping and blood pressure reactivity in medical patients. Journal of Behavioral Medicine, 12, 407-424.

Weinberger, D. A. (1990). The construct validity of the re- pressive coping style. In J. L. Singer (Ed.), Repression and dissociation: Implications for personality theory, psychopathology, and health (pp. 337-386). Chicago: University of Chicago Press.

Weinberger, D. A., Schwartz, G. E., \& Davidson, R. J. (1979). Low-anxious, high-anxious, and repressive coping styles: Psychometric patterns and behavioral and physiological responses to stress. Journal of Abnormal Psychology, 88, 369-380.

West, S. G., Aiken, L. S., \& Krull, J. L. (1996). Experimental personality designs: Analyzing categorical by continuous variable interactions. Journal of Personality, 64, $1-48$.

Winkielman, P., \& Cacioppo, J. T. (2001). Mind at ease puts a smile on the face: Psychophysiological evidence that processing facilitation elicits positive affect. Journal of Personality and Social Psychology, 81, 989-1000.

Received August 20, 2001 Revision received May 5, 2003 Accepted May 5, 2003

\title{
Call for Nominations: Rehabilitation Psychology
}

The APA Publications and Communications ( $\mathrm{P} \& \mathrm{C}$ ) Board has opened nominations for the editorship of Rehabilitation Psychology for the years 2006-2011. Bruce Caplan, $\mathrm{PhD}$, is the incumbent editor.

Candidates should be members of APA and should be available to start receiving manuscripts in early 2005 to prepare for issues published in 2006. Please note that the P\&C Board encourages participation by members of underrepresented groups in the publication process and would particularly welcome such nominees. Self-nominations are also encouraged.

Rehabilitation Psychology will transition from a division publication to an "all APA" journal in 2006 , and the successful candidate will be involved in making suggestions to the P\&C Board and APA Journals staff about the transition process.

Gary R. VandenBos, $\mathrm{PhD}$, and Mark Appelbaum, $\mathrm{PhD}$, have been appointed as cochairs for this search.

To nominate candidates, prepare a statement of one page or less in support of each candidate. Address all nominations to

\author{
Rehabilitation Psychology Search Committee \\ Karen Sellman, Search Liaison \\ Room 2004 \\ American Psychological Association \\ 750 First Street, NE \\ Washington, DC 20002-4242
}

The first review of nominations will begin December 8, 2003. The deadline for accepting nominations is December 15, 2003. 